Original

\title{
Analysis of the effects of fabrication parameters on the mechanical properties of Areca fine fiber-reinforced phenol formaldehyde composite using Taguchi technique
}

\author{
Chrispin Das MohanDas a, Athijayamani Ayyanar ${ }^{b, *}$, Sidhardhan Susaiyappan ${ }^{\mathrm{c}}$, \\ Ramanathan Kalimuthu ${ }^{\mathrm{d}}$ \\ ${ }^{a}$ Department of Mechanical Engineering, Bethlahem Institute of Engineering, Kanyakumari 629157, Tamil Nadu, India \\ ${ }^{\mathrm{b}}$ Department of Mechanical Engineering, Government College of Engineering, Bodi 625 513, Tamil Nadu, India \\ ${ }^{\mathrm{c}}$ Department of Civil Engineering, Government College of Engineering, Tirunelveli 627 007, Tamil Nadu, India \\ ${ }^{\mathrm{d}}$ Department of Mechanical Engineering, A.C. College of Engineering and Technology, Karaikudi 630 004, Tamil Nadu, India
}

Received 12 September 2016; accepted 8 March 2017

Available online 24 August 2017

\begin{abstract}
The influences of fabrication parameters such as the fiber content, fiber length, alkali concentration and alkali treatment duration on the mechanical properties (tensile and flexural strength) of Areca fine fiber (AFF)-reinforced phenol formaldehyde (PF) composite were investigated in the present study. The Taguchi's experimental design ( $\mathrm{L}_{27}$ orthogonal array) was used to prepare the composites and to analyze the mechanical properties of composites. The analysis of variance and signal-to-noise ratio with the Taguchi method were also used to understand the influence of the fabrication parameters on the tensile and flexural strength of the composite. Results show that the fiber content was the most influential fabrication parameter on both the tensile and flexural strength followed by the fiber length and the alkali treatment duration. The interaction between the fabrication parameters also has a significant effect on the tensile and flexural strength of the composite. The optimal combination of fabrication parameters to obtain the maximum tensile and flexural strength was found to be $\mathrm{FL}=10 \mathrm{~mm}, \mathrm{FC}=35 \mathrm{vol} \%, \mathrm{AC}=6 \%$ and $\mathrm{ATD}=1 \mathrm{~h}$.

(C) 2017 Universidad Nacional Autónoma de México, Centro de Ciencias Aplicadas y Desarrollo Tecnológico. This is an open access article under the CC BY-NC-ND license (http://creativecommons.org/licenses/by-nc-nd/4.0/).
\end{abstract}

Keywords: Areca fine fibers; Phenol formaldehyde; Composites; Mechanical properties; Taguchi's experimental design

\section{Introduction}

During the development of common materials, the human beings invented the useful material, it terms as composite, for their requirements. Composite materials are composed of the two phases: reinforcements (discontinuous phase) and matrix (continuous phase), in which the former is embedded into the latter to form the composite material in the desired shape. The discontinuous phases may be a fibrous or particulates, whereas the continuous phases may be a metal, ceramic, and polymer. Among these, the polymer matrix composite reinforced with the fibrous or particulate is focused by various research people

\footnotetext{
* Corresponding author.

E-mail address: athimania@gmail.com (A. Ayyanar).

Peer Review under the responsibility of Universidad Nacional Autónoma de México.
}

recently (Dai \& Fan, 2014, chap. 1; Faruk, Bledzki, Fink, \& Sain, 2012; Mohammed, Ansari, Pua, Jawaid, \& Saiful Islam, 2015). The reinforcements in polymer matrix composite are harder and stronger than the polymer matrix and improve its mechanical properties. Moreover, when the load is applied to the composite materials, the reinforcements act as the main load carrying element and provide strength, stiffness, and resistance against bends and breaks (Idrus, Hamdan, Rahman, \& Islam, 2011; Tawakkal, Cran, \& Bigger, 2014).

Nowadays, the researchers from the industries and academic institutions developed the polymer composite materials with the amalgamation of natural cellulose fibers due to their lightweight, lower cost, high specific properties, nontoxic, renewable and biodegradable, etc. The mechanical properties of these composites mainly depend on the fiber-matrix interfacial adhesion, the ability of the fiber and the matrix to stress transfer. The compatibility between the fiber and the matrix measures the 
adhesion between them, which is based on their nature; whereas the ability of the stress transfer is based on the geometry (Romanzini, Lavoratti, Ornaghi Jr, Amico, \& Zattera, 2013; Selvan \& Athijayamani, 2016). Unfortunately, the fibers and polymer cannot be compatible due to their natures, i.e. hydrophilic (natural cellulose fibers) and hydrophobic (polymers). Therefore, a natural cellulose fiber-reinforced polymer composite cannot be prepared for the better interfacial bonding without any chemical modifications (alkali, bleaching, silane, benzoylation, and acrylation, etc.) of the fiber or the polymer matrix (Dhakal, Zhang, \& Richardson, 2007; Norul Izani, Paridah, Anwar, Mohd Nor, \& H'Ng, 2013). Among these chemical modifications, the most commonly and widely used method is alkali treatment. It removes synthetic and natural impurities from the surface of the fibers incorrect portion, which depends on the concentration and treatment duration of alkali solution (Gassan, \& Bledzki, 1999; Tran, Bénézet, \& Bergeret, 2014). The above literature may conclude with the statement that the parameters, which influence the strength and stiffness of the composite, to the responsible for the high performance of natural cellulose fiber-reinforced polymer composites are fiber length, fiber loading and the modification of fibers through the suitable chemical agent with their suitable concentration and treatment duration. This paper is an attempt to analyze the effects of fabrication parameters like fiber loading (20, 35 and $50 \mathrm{vol} \%)$, fiber length $(4,10$ and $16 \mathrm{~mm})$, alkali concentration $(3,6$ and $9 \%)$ and alkali treatment duration (1, 3 and $5 \mathrm{~h})$ on the tensile strength of AFF/PF composite. The fabrication parameters are optimized with the maximum tensile strength. Composites are prepared with the four different fabrication parameters and analyzed based on the Taguchi's experimental design ( $\mathrm{L}_{27}$ orthogonal array). The Taguchi's experimental design along with the orthogonal array, the signal-to-noise ratio, and analysis of variance (ANOVA) are employed to identify the optimal combination of fabrication parameter to maximize the tensile strength and to find the percentage of contribution of each fabrication parameters on the tensile strength.

\section{Experimental details}

\subsection{Materials}

The areca fine fibers are collected from the Alphonse Fiber industry, Nagercoil, Tamil Nadu, India and used as reinforcement as received condition. The phenol formaldehyde resin (resole type) was used as the polymer matrix with the crosslinking agent and acidic catalyst.

\subsection{Plan for the experimental preparation and analysis of composite}

To observe the influence of the fiber length, fiber loading, alkali concentration and alkali treatment duration on the tensile and flexural strength of AFF/PF composite and to obtain the optimum (maximum) strength, a plan of the experiment is developed through Taguchi's design of experimental technique with signal-to-noise ratio and analysis of variance.
Table 1

Fabrication process parameters and their levels.

\begin{tabular}{lllll}
\hline Level & $\begin{array}{l}\text { Fiber } \\
\text { length } \\
(\mathrm{mm})(\mathrm{A})\end{array}$ & $\begin{array}{l}\text { Fiber } \\
\text { content } \\
(\mathrm{vol} \%)(\mathrm{B})\end{array}$ & $\begin{array}{l}\text { Alkali con- } \\
\text { centration } \\
(\%)(\mathrm{C})\end{array}$ & $\begin{array}{l}\text { Alkali treatment } \\
\text { duration }(\mathrm{h})(\mathrm{D})\end{array}$ \\
\hline 1 & 4 & 20 & 3 & 1 \\
2 & 10 & 35 & 6 & 3 \\
3 & 16 & 50 & 9 & 5 \\
\hline
\end{tabular}

The identification of the relationship among the various fabrication parameters and the important process parameters is very much essential because they influence the properties of composites. Taguchi technique is an engineering design method and focusing on determining the parameter settings producing the best level of performances with minimum variation. Therefore, the Taguchi experimental design can reduce experimental cycle time and cost and determine the significant factors affecting quality characteristics.

In traditional experimental design methods, the large number of experiments is carried out when the number of process parameters increases. So, the experimentation and their interpretation are too complex and are not easy. To overcome this difficulty, the Taguchi introduces a special design of orthogonal arrays to analyze the effects of the all the parameters on the output with only a minimum number of experiments. In this study, the number of parameters is four and the number of levels is three (Table 1). In this combination, the actual number of experiments is 81 , but according to the design of orthogonal array, $\mathrm{L}_{27}$ orthogonal array is chosen for the implementation of the plan.

\subsection{Preparation of composites}

Composites are prepared as per the Taguchi's experimental design using hand lay-up technique. First, the fibers are evenly spread into the mold box using a mechanical roller to ensure the even dispersion of fibers within the composite. Then, the PF resin is mixed with the cross-linking agent and acidic catalyst and stirred using a mechanical stirrer for $30 \mathrm{~min}$. After that, the resin mixture is poured into the mold containing the fibers in the random form. Finally, the mold box is closed and allowed to cure at room temperature for $48 \mathrm{~h}$.

\subsection{Testing of composites}

The tensile strength of the composite specimens was measured using FIE universal testing machine according to ASTM D638-10 at a crosshead speed of $2 \mathrm{~mm} / \mathrm{min}$. The flexural strength of composite specimens was measured on the same machine in accordance with ASTM D738-10 at a crosshead speed of $2 \mathrm{~mm} / \mathrm{min}$. All the tests were conducted at room temperature at atmospheric pressure. 


\subsection{Signal-to-noise ratio and ANOVA}

The results of mechanical tests obtained through the Taguchi's experimental design are then transformed into a signal-to-noise $(\mathrm{S} / \mathrm{N})$ ratio using popular software, namely MINITAB 15. The value of the $\mathrm{S} / \mathrm{N}$ ratio of strength values can be used to measure the deviation of the expected output values (performances) from the desired output values. There are three types of $\mathrm{S} / \mathrm{N}$ ratios for the analysis of the output values: the lower-the-better, the nominal-the-better and the higher-thebetter. Usually, the best output can be identified by the large value of the $\mathrm{S} / \mathrm{N}$ ratio as well as the optimum levels of parameters are also identified by the larger $\mathrm{S} / \mathrm{N}$ ratio regardless of the type of $\mathrm{S} / \mathrm{N}$ ratios. Moreover, the most influenced parameters on the outputs are identified by the ANOVA. It can be done by determining the percentage of contribution of each parameter. After the finding of optimal combination of the parameters with the best outputs, a confirmation test is performed to examine the selected combination of parameters. For the tensile and flexural strength values, the higher-the-better type of $\mathrm{S} / \mathrm{N}$ ratio is used for the analysis.

$\frac{\mathrm{S}}{\mathrm{N}}=\log \frac{1}{n}\left(\sum \frac{1}{y^{2}}\right)$

where $n$ is the number of observations and $y$ is the observed data.

\section{Results and discussion}

The experiments as per the $\mathrm{L}_{27}$ orthogonal array were conducted to observe the influence of four independent fabrication parameters and their three levels on the tensile and flexural strength of AFF/PF composites. The results for various combinations of fabrication parameters were obtained, analyzed using the commercial software MINITAB 15. Table 2 shows the average experimental results of the tensile and flexural strength and their corresponding $\mathrm{S} / \mathrm{N}$ ratio.

\subsection{Effects of fabrication parameters on the tensile strength of $A F F / P F$ composite}

The effects of fabrication parameters on the tensile strength of AFF/PF composites can be observed and analyzed through the analysis of the $\mathrm{S} / \mathrm{N}$ ratio. Table 3 gives the $\mathrm{S} / \mathrm{N}$ ratio values in the larger-the-better type for the tensile strength of composites. In Table 3, the term 'rank' denotes the effects of the fabrication parameters on the tensile strength. It can be seen that the fiber content is the most influencing fabrication parameter for tensile strength followed by the fiber length and alkali treatment duration. The alkali concentration had a much lower effect on the tensile strength of composites. The linear model coefficients for $\mathrm{S} / \mathrm{N}$ ratios of tensile strength are estimated with $R$-squared value of 0.955 .

The effects of fabrication parameters on the tensile strength of AFF/PF composites are also understood from Figure 1. It is observed that the tensile strength increases with fiber length up to $10 \mathrm{~mm}$ and then decreased by $16 \mathrm{~mm}$. The fiber content was also
Table 2

The average experimental results of the tensile and flexural strength and also their corresponding $\mathrm{S} / \mathrm{N}$ ratio.

\begin{tabular}{lllllllll}
\hline $\begin{array}{l}\text { Exp. } \\
\text { no. }\end{array}$ & $\begin{array}{l}\text { FL } \\
(\mathrm{mm})\end{array}$ & $\begin{array}{l}\text { FC } \\
(\mathrm{vol} \%)\end{array}$ & $\begin{array}{l}\text { AC } \\
(\%)\end{array}$ & $\begin{array}{l}\text { ATD } \\
(\mathrm{h})\end{array}$ & $\begin{array}{l}\text { TS } \\
(\mathrm{MPa})\end{array}$ & $\begin{array}{l}\text { S/N ratio } \\
\text { for TS }\end{array}$ & $\begin{array}{l}\text { FS } \\
(\mathrm{MPa})\end{array}$ & $\begin{array}{l}\text { S/N ratio } \\
\text { for FS }\end{array}$ \\
\hline 1 & 4 & 20 & 3 & 1 & 25.8 & 28.232 & 31.7 & 30.021 \\
2 & 4 & 20 & 6 & 3 & 22.4 & 27.005 & 30.5 & 29.686 \\
3 & 4 & 20 & 9 & 5 & 24.7 & 27.854 & 30.1 & 29.571 \\
4 & 4 & 35 & 3 & 3 & 26.5 & 28.465 & 36.9 & 31.341 \\
5 & 4 & 35 & 6 & 5 & 29.2 & 29.308 & 34.7 & 30.807 \\
6 & 4 & 35 & 9 & 1 & 27.6 & 28.818 & 37.2 & 31.411 \\
7 & 4 & 50 & 3 & 5 & 25.5 & 28.131 & 29.4 & 29.367 \\
8 & 4 & 50 & 6 & 1 & 27.3 & 28.723 & 29.9 & 29.513 \\
9 & 4 & 50 & 9 & 3 & 26.1 & 28.333 & 27.8 & 28.881 \\
10 & 10 & 50 & 3 & 1 & 26.7 & 28.530 & 32.3 & 30.184 \\
11 & 10 & 50 & 6 & 3 & 24.1 & 27.640 & 33.7 & 30.553 \\
12 & 10 & 50 & 9 & 5 & 22.8 & 27.159 & 31.6 & 29.994 \\
13 & 10 & 20 & 3 & 3 & 24.9 & 27.924 & 30.9 & 29.799 \\
14 & 10 & 20 & 6 & 5 & 21.8 & 26.769 & 24.4 & 27.748 \\
15 & 10 & 20 & 9 & 1 & 23.7 & 27.495 & 27.8 & 28.881 \\
16 & 10 & 35 & 3 & 5 & 31.2 & 29.883 & 30.5 & 29.686 \\
17 & 10 & 35 & 6 & 1 & 46.3 & 33.312 & 51.5 & 34.236 \\
18 & 10 & 35 & 9 & 3 & 35.5 & 31.005 & 42.6 & 32.588 \\
19 & 16 & 35 & 3 & 1 & 28.9 & 29.218 & 45.1 & 33.084 \\
20 & 16 & 35 & 6 & 3 & 26.6 & 28.498 & 41.8 & 32.424 \\
21 & 16 & 35 & 9 & 5 & 22.9 & 27.197 & 43.7 & 32.810 \\
22 & 16 & 50 & 3 & 3 & 24.5 & 27.783 & 34.9 & 30.857 \\
23 & 16 & 50 & 6 & 5 & 19.7 & 25.889 & 31.1 & 29.855 \\
24 & 16 & 50 & 9 & 1 & 21.2 & 26.527 & 35.6 & 31.029 \\
25 & 16 & 20 & 3 & 5 & 18.3 & 25.249 & 30.4 & 29.657 \\
26 & 16 & 20 & 6 & 1 & 22.3 & 26.966 & 32.8 & 30.317 \\
27 & 16 & 20 & 9 & 3 & 20.8 & 26.361 & 31.7 & 30.021 \\
\hline
\end{tabular}

Exp. $=$ experiment, $\mathrm{FL}=$ fiber length, $\mathrm{FC}=$ fiber content, $\mathrm{AC}=$ alkali concentration, and $\mathrm{ATD}=$ alkali treatment duration.

Table 3

Response table for S/N ratio (larger-the-better type) of tensile strength of AFF/PF composites.

\begin{tabular}{lcccc}
\hline Level & FL & FC & AC & ATD \\
\hline 1 & 28.32 & 27.10 & 28.16 & 28.65 \\
2 & 28.86 & 29.52 & 28.23 & 28.11 \\
3 & 27.08 & 27.64 & 27.86 & 27.49 \\
Delta & 1.78 & 2.43 & 0.37 & 1.15 \\
Rank & 2 & 1 & 4 & 3
\end{tabular}

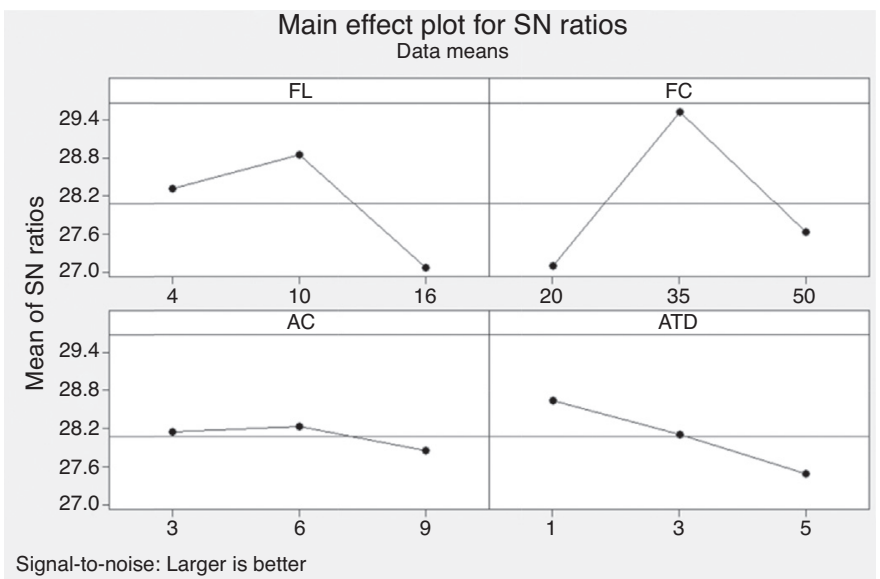

Fig. 1. Main effects plot for $\mathrm{S} / \mathrm{N}$ ratios of tensile strength of $\mathrm{AFF} / \mathrm{PF}$ composite. 
increasing the tensile strength of the composite up to $35 \mathrm{vol} \%$ and then reduces. The treatment of fibers with an alkali solution leads to increase in the tensile strength up to $6 \%$ and then started to decrease by $9 \%$. As alkali treatment duration increases, the tensile strength of the composite decreases.

The expected output was higher the tensile strength value. When the fiber lengths are at 4 and $16 \mathrm{~mm}$ the tensile strength value was minimized. In the composites having the fiber length of $4 \mathrm{~mm}$, the end points of fibers are more due to the short length of the fibers. It means that there is an insufficient fiber length to transmit the applied load. Therefore, the tensile strength of composite having the fiber length of $4 \mathrm{~mm}$ is minimized. On the other hand, in the composite having the fiber length of $16 \mathrm{~mm}$, the higher fiber length creates the improper fiber wetting by the matrix due to the increased fiber entanglement. In addition to the above reason, there is also a possibility of formation of the fiber or the matrix-rich areas due to the higher fiber length. Due to this, the tensile strength of the composite prepared with longer fiber length was minimized. Similarly, when the fiber contents are at 20 and $50 \mathrm{vol} \%$ the tensile strength was reduced. In 20 vol\% composites, there may be an improper transmission of the applied load to the AFFs due to the dispersion of the AFFs. It is confirmed that the addition of $20 \mathrm{vol} \%$ of AFFs is not a good reinforcement level to the PF resin. In $50 \mathrm{vol} \% \mathrm{com}-$ posites, the addition of the AFFs was minimizing the tensile strength of composite. This is may be due to the poor wettability between the fibers and the matrix by the insufficient matrix.

Alkali treatment of natural cellulose fibers is one of the chemical methods which can improve the mechanical properties of composites. Alkali treatment within the structure of natural fibers decreases the spiral angle as well as increases the molecular orientation of the cellulose chain (Gassan \& Bledzki, 1999). It also produces the rougher surface of the structure of the fibers which increase the fiber-matrix interfacial adhesion (Mohanty, Khan, \& Hinrichsen, 2000; Valadez-Gonzalez, Cervantes-Uc, Olayo, \& Herrera-Franco, 1999). Alkali treatment of $6 \%$ at $1 \mathrm{~h}$ gives the maximum tensile strength value. It may be due to the fact that the treatment of fibers with the $6 \%$ of the alkali solution increases the interfacial bonding between the fiber and the matrix by removing the artificial and natural impurities from the structure of the fibers. By removing the impurities, the surface of the fibers becomes rougher which leads to the better mechanical interlocking between the fiber and the matrix (Mohanty, Mubarak, \& Hinrichsen, 2000). But, in $9 \%$ of alkali treatment at all treatment duration, the tensile strength was decreased. It may be due to the characteristics losing of the fibers. The high percentage of the alkali solution may completely dissolve the composition of the fibers. Therefore, the fibers lose their unique characteristics. In the case of alkali treatment duration, the treatment of fibers for $1 \mathrm{~h}$ shows the maximum tensile strength. The higher the duration of treatment may reduce the fiber strength which results in reduction of composite strength. From the above discussion, it can be concluded that the optimal fabrication parameters to obtain maximum tensile strength is found to be $\mathrm{FL}=10 \mathrm{~mm}, \mathrm{FC}=35 \mathrm{vol} \%, \mathrm{AC}=6 \%$ and $\mathrm{ATD}=1 \mathrm{~h}$.
Table 4

Response table for $\mathrm{S} / \mathrm{N}$ ratio (larger-the-better type) of flexural strength of AFF/PF composites.

\begin{tabular}{lcccc}
\hline Level & FL & FC & AC & ATD \\
\hline 1 & 30.07 & 29.52 & 30.44 & 30.96 \\
2 & 30.41 & 32.04 & 30.57 & 30.68 \\
3 & 31.12 & 30.03 & 30.58 & 29.94 \\
Delta & 1.05 & 2.52 & 0.13 & 1.02 \\
Rank & 2 & 1 & 3 & 4 \\
\hline
\end{tabular}

\subsection{Effects of fabrication parameters on the flexural strength of AFF/PF composites}

The response Table 4 shows the fiber content as influencing parameter for flexural strength, followed by fiber length and alkali treatment duration. For the flexural strength also, the alkali concentration had a lower effect compared to the other fabrication parameters. The linear model coefficients for $\mathrm{S} / \mathrm{N}$ ratios of flexural strength are estimated with $R$-squared value of 0.918 . Figure 2 shows the main effect plots for flexural strength. It is observed that the flexural strength of composite increases with increase in fiber content up to $35 \mathrm{vol} \%$ and then dropped like in tensile strength. In $35 \mathrm{vol} \%$ of fibers, the better interfacial bonding between the fibers and the matrix is obtained with the better mechanical interlocking which results in the maximum mechanical properties. The flexural strength decreases with the further addition (50 vol\%) of AFFs. It may be due to the poor wettability between the fiber and the matrix by the insufficient matrix material. The flexural strength of composite is also influenced by the fiber length. Composites having the fiber length of $10 \mathrm{~mm}$ show the maximum level of flexural strength as compared to the other fiber length composites. When using the fibers with the smaller length $(4 \mathrm{~mm})$ in the polymer composites, composites could not attain the expected level of property levels because there are many fiber ends which could not efficiently transfer the applied load to the matrix. Therefore, the composites fail quickly within the range of applied load. On the other hand, when using the fibers with the larger length $(16 \mathrm{~mm})$, the improper fiber wetting is created due to increased fiber entanglement with the

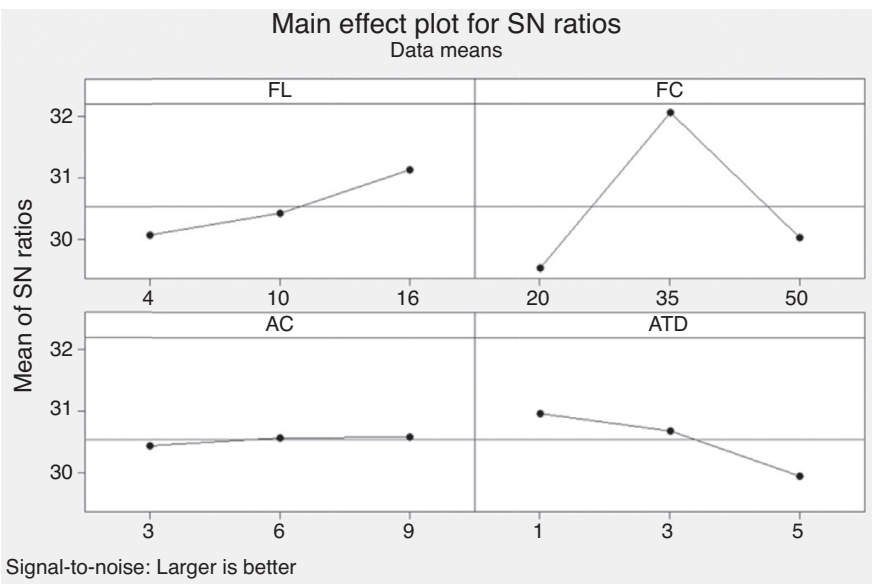

Fig. 2. Main effects plot for $\mathrm{S} / \mathrm{N}$ ratios of the flexural strength of $\mathrm{AFF} / \mathrm{PF}$ composite. 
fiber-to-fiber contact. Moreover, there is a possibility of forming the fiber-rich and the matrix-rich areas within the prepared composites. Therefore, the stress transfer could not be efficient between the fiber and the matrix, which results in failure of the composites.

The flexural strength increases with increase in alkali concentration up to $6 \%$, after that, decreases with the further increment of alkali concentration as shown in Figure 2. Even though the treatment duration is low, the higher concentration of alkali solution is damaging the structure of the fiber which results in quick breakage of fibers during testing. Moreover, the alkali treatment duration decreases the flexural strength of composite by its increment in treatment duration. The probable reason is that the higher treatment duration damages the fiber, i.e. the reduction of fiber strength. Therefore, the optimal fabrication parameters to obtain maximum flexural strength was also found to be $\mathrm{FL}=10 \mathrm{~mm}$, $\mathrm{FC}=35$ vol $\%, \mathrm{AC}=6 \%$ and $\mathrm{ATD}=1 \mathrm{~h}$.

The large $\mathrm{S} / \mathrm{N}$ ratio value was obtained from the above mentioned combination of fiber length, fiber content, alkali concentration and alkali treatment duration. From the response tables for $\mathrm{S} / \mathrm{N}$ ratio for the larger-the-better type, it can be seen that the fiber content is a dominant fabrication parameter on the tensile and flexural strength of composite followed by the fiber length and alkali treatment duration. The alkali concentration had a much lower effect on the tensile and flexural strength of composites.

\subsection{Analysis of variance}

The results of ANOVA for tensile and flexural strength for the confidence level of $95 \%$ were shown in Tables 5 and 6 . In

Table 5

Analysis of variance for $\mathrm{S} / \mathrm{N}$ ratios of tensile strength of $\mathrm{AFF} / \mathrm{PF}$ composite.

\begin{tabular}{lrrrrrrr}
\hline Source & DF & Seq SS & Adj SS & Adj MS & $F$-test & $\begin{array}{l}P \text { - } \\
\text { value }\end{array}$ & $\begin{array}{l}\% \text { of con- } \\
\text { tribution }\end{array}$ \\
\hline FL & 2 & 15.0158 & 15.0158 & 7.5079 & 14.78 & 0.005 & 22.03 \\
FC & 2 & 29.2386 & 29.2386 & 14.6193 & 28.78 & 0.001 & 42.89 \\
AC & 2 & 0.7001 & 0.7001 & 0.3501 & 0.69 & 0.538 & 01.03 \\
ATD & 2 & 6.0002 & 6.0002 & 3.0001 & 5.91 & 0.038 & 08.80 \\
FL*FC & 4 & 9.3532 & 9.3532 & 2.3383 & 4.60 & 0.048 & 13.72 \\
FL*AC & 4 & 0.8344 & 0.8344 & 0.2086 & 0.41 & 0.796 & 01.22 \\
FL*ATD & 4 & 3.9823 & 3.9823 & 0.9956 & 1.96 & 0.220 & 05.84 \\
Residual error & 6 & 3.0478 & 3.0478 & 0.5080 & & & 04.47 \\
Total & 26 & 68.1725 & & & & & 100 \\
\hline
\end{tabular}

Table 6

Analysis of variance for $\mathrm{S} / \mathrm{N}$ ratios of the flexural strength of AFF/PF composite.

\begin{tabular}{lrrrrrrr}
\hline Source & DF & Seq SS & Adj SS & Adj MS & $F$-test & $\begin{array}{l}P \text { - } \\
\text { value }\end{array}$ & $\begin{array}{l}\text { \% of con- } \\
\text { tribution }\end{array}$ \\
\hline FL & 2 & 5.1707 & 5.1707 & 2.5854 & 3.38 & 0.104 & 9.27 \\
FC & 2 & 32.0197 & 32.0197 & 16.0099 & 20.93 & 0.002 & 57.41 \\
AC & 2 & 0.1010 & 0.1010 & 0.0505 & 0.07 & 0.937 & 0.18 \\
ATD & 2 & 4.9989 & 4.9989 & 2.4995 & 3.27 & 0.110 & 8.96 \\
FL*FC & 4 & 3.9038 & 3.9038 & 0.9760 & 1.28 & 0.375 & 6.99 \\
FL*AC & 4 & 1.7381 & 1.7381 & 0.4345 & 0.57 & 0.696 & 3.12 \\
FL*ATD & 4 & 3.2495 & 3.2495 & 0.8124 & 1.06 & 0.450 & 5.83 \\
Residual error & 6 & 4.5886 & 4.5886 & 0.7648 & & & 8.23 \\
Total & 26 & 55.7704 & & & & & 100 \\
\hline
\end{tabular}

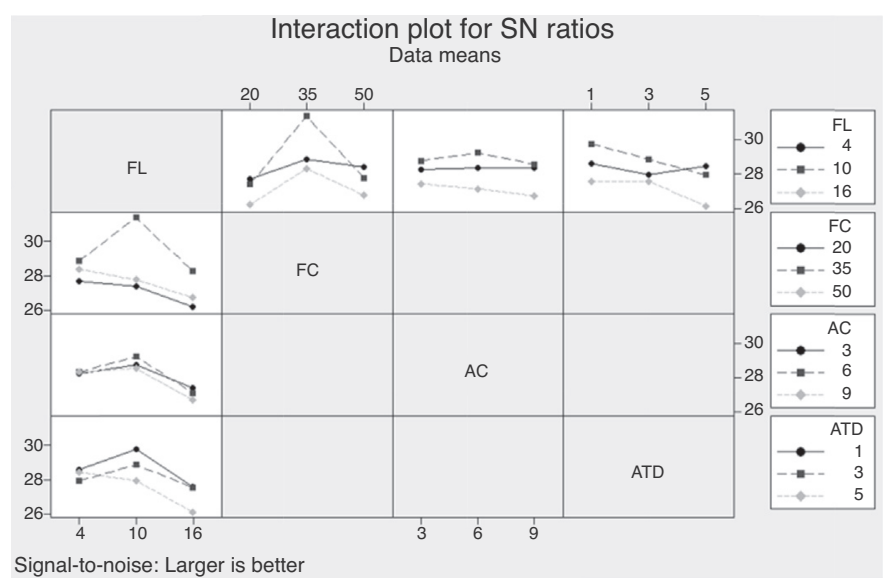

Fig. 3. Interaction plot for $\mathrm{S} / \mathrm{N}$ ratios of the tensile strength of AFF/PF composite.

general, the analysis of variance can be used to understand the influence of the process parameters on the responses quantitatively. From Table 5, it is clearly identified that the fiber content has the highest influence $(42.89 \%)$ on tensile strength followed by fiber length $(22.03 \%)$ and alkali treatment duration $(8.80 \%)$. In the case of interaction terms in Table 5, interaction between fiber length and fiber content has $13.72 \%$, interaction between the fiber length and alkali concentration has $1.22 \%$ and interaction between the fiber length and alkali treatment duration has $5.84 \%$. The above results indicate that interaction terms also had a significant effect on tensile strength. Interaction plot for $\mathrm{S} / \mathrm{N}$ ratios of tensile strength is shown in Figure 3.

The fiber content has also maximum statistical influence $(43.26 \%)$ on the flexural strength followed by fiber length $(29.08 \%)$ and alkali treatment duration $(10.36 \%)$, as shown in Table 6. Table 6 also shows that interaction between the fiber content and the fiber length, the fiber content and alkali concentration and also the alkali concentration and the alkali treatment duration has influences of $8.78 \%, 14.47 \%$ and $12.76 \%$, respectively on the flexural strength of AFF/PF composites. Interaction plot for $\mathrm{S} / \mathrm{N}$ ratios of flexural strength is shown in Figure 4.

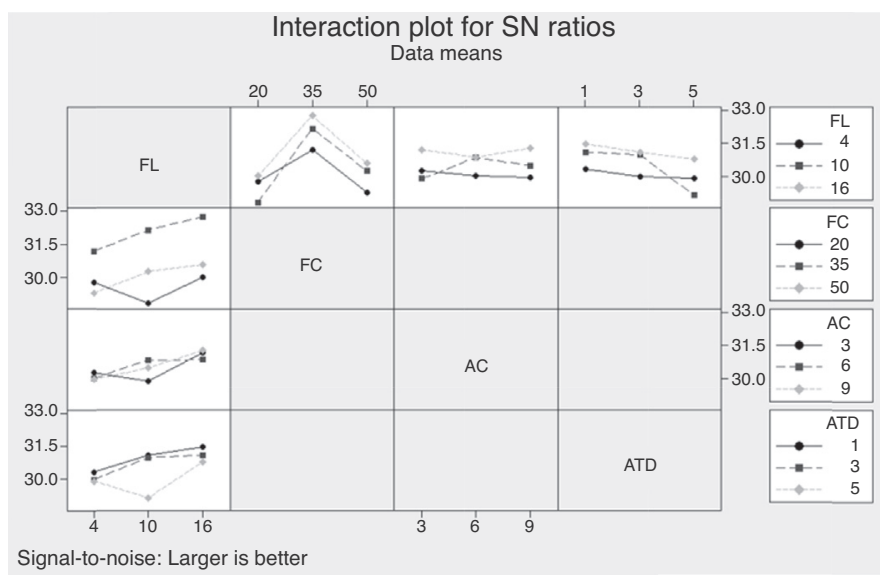

Fig. 4. Interaction plot for $\mathrm{S} / \mathrm{N}$ ratios of the flexural strength of $\mathrm{AFF} / \mathrm{PF}$ composite. 


\section{Conclusions}

The AFF/PF composites were prepared by Taguchi's experimental design and their fabrication parameters and the mechanical properties were analyzed signal-to-noise ratio and analysis of variance. The results revealed that the fiber content is the most dominant fabrication parameter for the tensile strength among the four different parameters. In the flexural strength, dominant fabrication parameter is also found to be the fiber content. From the main effect plots of tensile strength, it can be seen that the tensile strength of composite increases with the increase of the fiber length, fiber content and alkali concentration for certain limit and then decreases. But, the tensile strength of composite decreased by the increasing of the alkali treatment duration. Similar observations were also obtained for the flexural strength for its main effect plot. The optimal combination of fabrication parameters was obtained by the Taguchi analysis for both the tensile and flexural strength of AFF/PF composite. The results of the optimal fabrication parameters were the maximum tensile and flexural strength. Influencing percentages of each fabrication parameter on the mechanical properties were obtained by analysis of variance.

\section{Conflict of interest}

The authors have no conflicts of interest to declare.

\section{References}

Dai, D., \& Fan, M. (2014). Wood fibres as reinforcements in natural fibre composites: Structure, properties, processing and applications. In Natural fibre composites: Materials, processes and properties. pp. 3-65. Woodhead Publishing. http://dx.doi.org/10.1533/9780857099228.1.3

Dhakal, H. N., Zhang, Z. Y., \& Richardson, M. O. W. (2007). Effect of water absorption on the mechanical properties of hemp fibre reinforced unsaturated polyester composites. Composites Science and Technology, 67(7-8), 1674-1683. http://dx.doi.org/10.1016/j.compscitech.2006.06.019

Faruk, O., Bledzki, A. K., Fink, H.-P., \& Sain, M. (2012). Biocomposites reinforced with natural fibers: 2000-2010. Progress in Polymer Science, 37(11), 1552-1596. http://dx.doi.org/10.1016/j.progpolymsci.2012.04.003
Gassan, J., \& Bledzki, A. K. (1999). Possibilities for improving the mechanical properties of jute/epoxy composites by alkali treatment of fibres. Composites Science and Technology, 59(9), 1303-1309. http://dx.doi.org/10.1016/S0266-3538(98)00169-9

Idrus, M. A. M. M., Hamdan, S., Rahman, M. R., \& Islam, M. S. (2011). Treated tropical wood sawdust-polypropylene polymer composite: Mechanical and morphological study. Journal of Biomaterials and Nanobiotechnology, 2, 435-444. http://dx.doi.org/10.4236/jbnb.2011.24053

Mohammed, L., Ansari, M. N. M., Pua, G., Jawaid, M., \& Saiful Islam, M. (2015). A review on natural fiber reinforced polymer composite and its applications. International Journal of Polymer Science, 2015, 1-15. http://dx.doi.org/10.1155/2015/243947

Mohanty, A. K., Khan, M. A., \& Hinrichsen, G. (2000). Influence of chemical surface modification on the properties of biodegradable jute fabrics-polyester amide composites. Composites Part A: Applied Science and Manufacturing, 31, 143-150. http://dx.doi.org/10.1016/S1359-835X(99)00057-3

Mohanty, A. K., Mubarak, A. K., \& Hinrichsen, G. (2000). Surface modification of jute and its influence on performance of biodegradable jute-fabric/biopol composites. Composites Science and Technology, 60(7), 1115-1124. http://dx.doi.org/10.1016/S0266-3538 (00)00012-9

Norul Izani, M. A., Paridah, M. T., Anwar, U. M. K., Mohd Nor, M. Y., \& H'Ng, P. S. (2013). Effects of fiber treatment on morphology, tensile and thermogravimetric analysis of oil palm empty fruit bunches fibers. Composites Part B: Engineering, 45(1), 1251-1257. http://dx.doi.org/10.1016/j.compositesb.2012.07.027

Romanzini, D., Lavoratti, A., Ornaghi, H. L., Jr., Amico, S. C., \& Zattera, A. J. (2013). Influence of fiber content on the mechanical and dynamic mechanical properties of glass/ramie polymer composites. Materials and Design, 47, 9-15. http://dx.doi.org/10.1016/j.matdes.2012.12.029

Selvan, M. G. A., \& Athijayamani, A. (2016). Mechanical properties of fragrant screwpine fiber reinforced unsaturated polyester composite: Effect of fiber length, fiber treatment and water absorption. Fibers and Polymers, 17(1), 104-116. http://dx.doi.org/10.1007/s12221-016-5593-x

Tawakkal, I. S. M. A., Cran, M. J., \& Bigger, S. W. (2014). Effect of kenaf fibre loading and thymol concentration on the mechanical and thermal properties of PLA/kenaf/thymol composites. Industrial Crops and Products, 61, 74-83. http://dx.doi.org/10.1016/j.indcrop.2014.06.032

Tran, T. P. T., Bénézet, J.-C., \& Bergeret, A. (2014). Rice and Einkorn wheat husks reinforced poly(lactic acid) (PLA) biocomposites: Effects of alkaline and silane surface treatments of husks. Industrial Crops and Products, 58, 111-124. http://dx.doi.org/10.1016/j.indcrop.2014.04.012

Valadez-Gonzalez, A., Cervantes-Uc, J. M., Olayo, R. J. I. P., \& Herrera-Franco, P. J. (1999). Effect of fiber surface treatment on the fiber-matrix bond strength of natural fiber reinforced composites. Composites Part B: Engineering, 30(3), 309-320. http://dx.doi.org/10.1016/ S1359-8368(98)00054-7 